\title{
Probiotics in Clostridium difficile infection: reviewing the need for a multistrain probiotic
}

\author{
M. Hell ${ }^{1,2}$, C. Bernhofer ${ }^{1}$, P. Stalzer ${ }^{1,2}$, J.M. Kern² and E. Claassen ${ }^{3,4}$ \\ ${ }^{1}$ Department of Hospital Epidemiology and Infection Control, Salzburg University Hospital, Paracelsus Medical University, \\ Strubergasse 21, 5020 Salzburg, Austria; ${ }^{2}$ Division of Medical Microbiology, Institute of Laboratory Medicine, Salzburg \\ University Hospital, Paracelsus Medical University, Strubergasse 21, 5020 Salzburg, Austria, ${ }^{3}$ Erasmus Medical Centre, \\ Department of Virology, P.O. Box 2040, 3000 CA Rotterdam, the Netherlands; ${ }^{4}$ Athena Institute, VU Amsterdam, De \\ Boelelaan 1085, 1081 HV Amsterdam, the Netherlands; prof.eric.claassen@gmail.com
}

Received: 24 May 2012/ Accepted: 4 February 2013

(c) 2013 Wageningen Academic Publishers

\begin{abstract}
In the past two years an enormous amount of molecular, genetic, metabolomic and mechanistic data on the hostbacterium interaction, a healthy gut microbiota and a possible role for probiotics in Clostridium difficile infection (CDI) has been accumulated. Also, new hypervirulent strains of $C$. difficile have emerged. Yet, clinical trials in CDI have been less promising than in antibiotic associated diarrhoea in general, with more meta-analysis than primary papers on CDI-clinical-trials. The fact that $C$. difficile is a spore former, producing at least three different toxins has not yet been incorporated in the rational design of probiotics for (recurrent) CDI. Here we postulate that the plethora of effects of $C$. difficile and the vast amount of data on the role of commensal gut residents and probiotics point towards a multistrain mixture of probiotics to reduce CDI, but also to limit (nosocomial) transmission and/or endogenous reinfection. On the basis of a retrospective chart review of a series of ten CDI patients where recurrence was expected, all patients on adjunctive probiotic therapy with multistrain cocktail (Ecologic ${ }^{\circ} \mathrm{AAD} / \mathrm{OMNiBiOTiC}{ }^{\odot}$ 10) showed complete clinical resolution. This result, and recent success in faecal transplants in CDI treatment, are supportive for the rational design of multistrain probiotics for CDI.
\end{abstract}

Keywords: Clostridium difficile, colonisation of GI tract, colonisation resistance, diarrhoea, intestinal mucosa

\section{Introduction}

Clostridium difficile infection (CDI) is the most significant bacterial cause of hospital acquired (nosocomial) diarrhoea in adults (Bauer and Van Dissel, 2009). The severity of CDI ranges from mild, usually self-limiting, diarrhoea to fulminant colitis, toxic megacolon and death. $C$ difficile colonises and can be isolated from $0-5 \%$ of healthy adults (Hautmann et al., 2011; Hell et al., 2012; Moudgal and Sobel 2012; Parkes et al., 2009). However, this can increase to $39 \%$ in hospitalised patients (Hickson, 2011; McFarland, 2011) depending on treatment and local conditions, with individuals over the age of 65 being prime targets and age itself being a predisposing factor (referred to as 'inflammaging' and 'immunosenescence'; Islam et al., 2012).
C. difficile is a gram-positive, anaerobic, spore forming bacillus first described in 1935 after isolation from the stool of a healthy newborn (Bacillus difficilis; Hall and O'Toole, 1935). Normally, neonates develop a stable microbiota (even when colonised with $C$. difficile) without clinical problems, probably because they are short of (adequately expressed) toxin receptors in the still immature gut. Not until 1978 was $C$. difficile recognised as an opportunistic pathogen for its antibiotic-associated diarrhoea and pseudomembranous colitis. CDI has rapidly increased since the 1990s with alarming rise since 2000 (1999-2007: 25\% incidenceincrease per year in USA and $750 \%$ fatality rate increase in UK; Kelly, 2009) when the novel and fluoroquinolone resistant strain of PCR ribotype 027 spread and accounted for severe disease and over $40 \%$ of isolates (Islam et al., 
2012). Currently, CDI incidence rates are still high, but have dropped due to rapid diagnosis, improved infection control practice, root cause analysis, isolation of cases/ patients, and restricted use of antibiotics (stewardship). Since the problem with nosocomial infections also lies with spore-contaminated facilities and asymptomatic carriers (high IgG anti-toxin titers; Kyne et al., 2000), transmission reduction, in patients and health-care-workers alike, is an essential element in infection control.

\section{Clostridium difficile infection (mainly clinically manifested as diarrhoea)}

\section{General aspects}

The normal microbiota inhibits (opportunistic) pathogen growth and toxin release. This function is reduced after gut-damage and demonstrably so in faecal samples of antibiotic-treated patients (Parkes et al., 2009). Causes for microbiota-damage are shown at level 2 in Figure 1. Risk factors for microbiota damage are for example age, proton pump inhibitors (PPI), tube feeding and parenteral nutrition (Hautmann et al., 2011). After initial disturbance of the resident microbiota other factors can exacerbate the condition by causing an unwanted bacterial overgrowth (Figure 1:3) resulting in a mild (osmotic) diarrhoea that is usually self limiting (in over $75 \%$ of cases). When bacterial toxins are produced in sufficient amounts they will bind and structurally damage epithelial cells and/or the tight junctions, and the gut barrier is compromised (frequently also leading to bloody stools). This will then lead to an inflammatory cascade also involving the nervous system, which intensifies the diarrhoea. The reduction in fermentation also gives a reduction in the production of short chain fatty acids (SCFA) which normally provide energy and stimulation to colonocytes. Again, a large part of these violent episodes of diarrhoea is self limiting. When the immune system, diet and general condition of the patient are optimal, the resident microbiota will return and the cellular damage will be repaired by normal cellular regeneration (from crypt to apex of the villi 3-5 days). Prebiotic fibres like galacto- and fructo-oligosaccharides will accelerate restoration by preferentially creating a beneficial bifidogenic milieu whereas 'simple' sugars will enhance growth of opportunistic pathogens (Kelly, 2008). Similar beneficial effects as with prebiotics (specific vegetables in diet and/ or supplements like inulin) can be observed by oral intake of billons probiotic bacteria). Since the bacteria in the gut will always be counteracted by the (healthy) immune system (gut associated lymphoid tissue) only those bacteria that were considered 'self' in early life will persist in view of the gut immune tolerance they enjoy. Hence, the same profile fingerprint of bacteria will emerge after a dysbiosis episode. In any case, the balance is usually restored after several weeks. Since probiotics do not permanently colonise the gut and are non-invasive, they will disappear (average half life 5-7 days) when no longer ingested (Mercenier et al., 2000).

\section{Clostridum difficile specific aspects}

CDI has a number of specific properties making it the major nosocomial diarrhoea in adults. Firstly, CDI is particularly known for its specific risk factors age, use of antibiotics and hospitalisation (Hickson, 2011). When properly diagnosed, CDI is usually treated by withdrawal of the precipitating antibiotic, avoidance of anti-peristaltic agents and treatment with metronidazole or vancomycin for non-metronidazole-responders (Cohen et al., 2010) or severe cases. Still, up to a quarter of all patients will develop recurrent CDI (Hickson 2011), with those that experience such a relapse having a 50-60\% risk of further recurrence (Bauer and Van Dissel, 2009). This is particularly so because of hypervirulent strains (like ribotypes 027, 078 and 106) with more severe disease, increased mortality, resistance to fluoroquinolones and higher relapse rates (Cartman et al., 2010). Additional mortality by these hypervirulent strains is calculated to be between 6-12\% (Parkes et al., 2009). Although some of these recurrent cases are due to exogenous reinfection by ongoing exposure to spores in the environment, most exhibit the same bacterial strain of the first episode. Evidently, neither the first antibiotic nor vancomycin restored the gut microbiota, nor did they reduce the exposure to spores in the environment, the comorbidity or other CDI specific host risk factors (Bauer and van Dissel, 2009). Fidaxomicin, a recently available anti-CDI drug has a very specific mode of action against $C$. difficile and does, therefore, less harm to the gut microbiota than any other comparable anti-C. difficile antibiotics (Tschudin-Sutter et al., 2012). Fidaxomicin is also described as preserving the intestinal microbiome during and after treatment of CDI and reducing both toxin reexpressions and recurrence of CDI (Louie et al., 2012).

CDI starts with ingested (or resident) spores germinating in the colon and the bacteria establishing/maintaining themselves through specific adhesion (Islam et al., 2012). CDI is toxin mediated (Figure 1: 4). Two large (approx. $300 \mathrm{kDa}$ ) protein exotoxins, TcdA and TcdB, are produced, of which TcdB is clearly the main virulence factor as demonstrated by $\mathrm{TcdA}^{-\mathrm{ve}} \mathrm{B}^{+\mathrm{ve}}$ strains. The hypervirulent strain ribotype 027 produces an additional 'binary' toxin (CDT, an actin-specific ADP ribosyltransferase) whose role is not yet established, although it potentiates TcdA/B toxicity (Tschudin-Sutter et al., 2012). TcdA binds to the apical side of gut epithelial cells (to gp96, a C. difficile toxin A receptor) and causes cytoskeletal modification and tight junction disruption. This in turns facilitates binding of TcdB to the basal lamina leading to vascular permeability, release of neuropeptides (substance P, CGRP/calcitonin gene-related peptide and neurotensin), recruitment of white blood cells, pro-inflammatory cytokines (leukotrienes, 


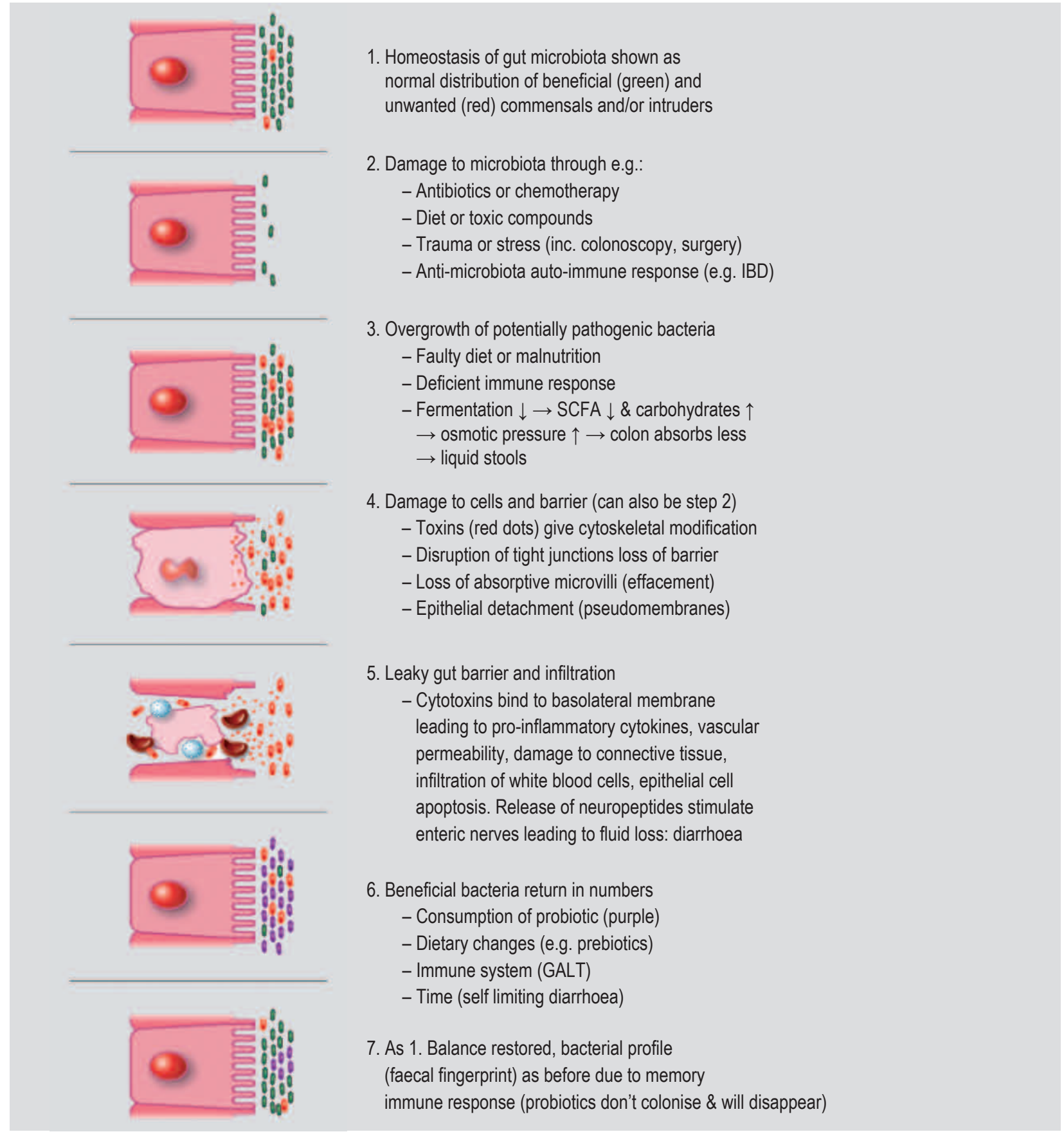

Figure 1. Homeostasis, damage, barrier/function-loss and repair of the gut epithelium: role of microbiota and probiotics. SCFA = short chain fatty acids; GALT = gut-associated lymphoid tissue.

$\left.\mathrm{PGE}_{2}, \mathrm{TNF} \alpha, \mathrm{IL}-1, \mathrm{IL}-6\right)$ epithelial cell apoptosis, pseudomembrane (PM-colitis) formation, connective tissue degradation, fluid exudation/secretion and subsequently diarrhoea and frequently also bloody stools. In short, $C$ difficile is pathogenetically unique in establishing a bona fide necro-inflammatory reaction activating mast cells, nerves, vascular endothelium and immune cells in addition to disruption of tight junctions (Hodges and Gill, 2010).

\section{Probiotics for prevention and treatment of diarrhoea}

\section{Maintenance of homeostasis and luminal effects}

As shown in Figure 2, both the commensals in a normal microbiota as well as ingested probiotic products will assist in defending the gut against colonisation by exogenous microorganisms. This mechanism is called colonisation resistance (Wolvers et al., 2010). In a single cell to single 
Table 1. Contributions of electrogenic versus electroneutral components of ion absorption at the basis of Clostridium difficile diarrhoea mechanisms. ${ }^{\text {a,b }}$

\begin{tabular}{|c|c|c|c|c|}
\hline Diarrhoea because of & Mechanism through & Molecules involved & Relevant for C. difficile & Role of probiotics ${ }^{c}$ \\
\hline $\begin{array}{l}\text { Increased secretion of } \\
\text { electrolytes (CLCA })^{1}\end{array}$ & $\begin{array}{l}\text { Overproduction of cAMP } \\
\text { gives activation of protein } \\
\text { kinase } \mathrm{A} \text { and opens CFTR } \\
\text { and } \mathrm{Cl}^{-} \text {secretion }\end{array}$ & CFTR and CLCA ${ }^{1}$ & $\begin{array}{l}\text { Increased } \mathrm{Cl}^{-} \text {secretion through } \\
\text { neuropeptides (substance P, } \\
\text { CGRP and neurotensin) }\end{array}$ & $\begin{array}{l}\text { Bifidobacteria dose dependently } \\
\text { inhibit (CFTR) } \mathrm{Cl}^{-} \text {secretion }{ }^{3} \text { and } \\
\text { promote intestinal homeostasis } \\
\text { one step downstream epithelial } \\
\mathrm{Ca}^{2+} \text { mobilisation }\end{array}$ \\
\hline $\begin{array}{l}\text { Reduced sodium } \\
\text { absorption }\end{array}$ & $\begin{array}{l}\text { Luminal membrane } \mathrm{Na}+\text { and } \\
\mathrm{H}+\text { exchange isoforms }\end{array}$ & NHE3 (aka SLC9A3) & $\begin{array}{l}\text { TcdB inactivates Rho-kinase } \\
\text { inhibitor altering activity and } \\
\text { distribution of } \mathrm{NHE}^{4}\end{array}$ & $\begin{array}{l}\text { Butyrate produced by probiotics } \\
\text { increases } \mathrm{NaCl} \text { absorption } \\
\text { by NHE3 stimulation and } \\
\text { transcription }^{5}\end{array}$ \\
\hline $\begin{array}{l}\text { Reduced chloride } \\
\text { absorption, } \\
\text { increased } \mathrm{HCO}_{3} \\
\text { secretion }\end{array}$ & $\begin{array}{l}\text { Apical anion exchange } \\
\text { mediating } \mathrm{Cl}^{-} \text {absorption } \\
\text { (seen in congenital } \\
\text { chloride diarrhoea) }\end{array}$ & DRA & As for other infectious diarrhoea & $\begin{array}{l}\text { LPA or Lactobacillus acidophilus } \\
\text { increase surface expression of } \\
\text { DRA giving increased chloride } \\
\text { absorption } \\
6,7\end{array}$ \\
\hline $\begin{array}{l}\text { Reduced water } \\
\text { absorption }\end{array}$ & ENS links directly with $A Q P^{8}$ & AQP, ANG, OXT & $\begin{array}{l}\text { Hypothesis: lactic acid upregulates } \\
\text { AQP4, which facilitates oedema } \\
\text { elimination in diseases causing } \\
\text { vasogenic }{ }^{10} \text { (vessel leak) } \\
\text { oedema }\end{array}$ & $\begin{array}{l}\text { Consumption of } L \text { acidophilus } \\
\text { led to higher gene expression } \\
\text { of water and ion homeostasis } \\
\text { regulators }{ }^{11}\end{array}$ \\
\hline $\begin{array}{l}\text { Reduced sodium and } \\
\text { glucose absorption }\end{array}$ & Inactivation of SGLT-1 & SGLT-1 & As for other infectious diarrhoea ${ }^{12}$ & $\begin{array}{l}\text { Microbiota influences expression } \\
\text { of SGLT-1 }{ }^{13}\end{array}$ \\
\hline $\begin{array}{l}\text { Loss of barrier } \\
\text { function, increased } \\
\text { paracellular } \\
\text { permeability }\end{array}$ & Altered tight junctions ${ }^{14,15}$ & $\begin{array}{l}\text { claudin-1, ZO-1, } \\
\text { ZO-2, occludin }\end{array}$ & $\begin{array}{l}\text { TcdA modifies cytoskeleton and } \\
\text { disrupts tight junctions }\end{array}$ & $\begin{array}{l}\text { Probiotics upregulate genes } \\
\text { coding for de novo synthesis of } \\
\text { claudin and occludin } \\
16,17\end{array}$ \\
\hline \multicolumn{5}{|c|}{ 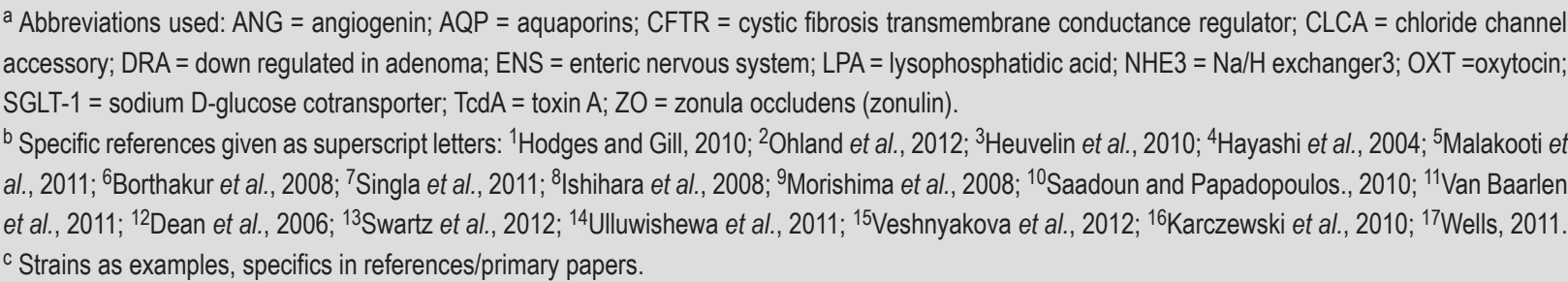 } \\
\hline
\end{tabular}

cell communication mechanism called quorum sensing some bacteria are able to down-regulate gene expression of pathogens, thereby decreasing virulence factors and/ or growth (Sherman et al., 2009). Furthermore, lactic acid bacteria produce a plethora of anti-microbial compounds including SCFAs, such as acetic, propionic, caproic and butyric acid, but also hydrogen peroxide, ethanol, acetaldehyde, diactyl, and carbon dioxide - all derived as either oxygen-catabolites or sugar-catabolites. Similarly, toxic compounds as fat and amino acid metabolites are produced, such as 3- and 4-hydroxy fatty acids, phenyllactic acid, aromatic and heterocyclic molecules. De novo protein synthesis by lactic acid bacteria results in antifungals, bacteriocins like reuterin and reutericyclin, and a host of low molecular mass peptides and cyclic peptides (see De Vuyst et al., 2009). Next to the bactericidal and bacteriostatic actions, these compounds can also downregulate expression of virulence factors, e.g. adherence molecules normally expressed by pathogens (Cadieux et al., 2009). Not only does the production of these compounds prevent dysbiosis in the gut, but this also explains why lactic acid bacteria have been used successfully for over three thousand years to conserve and sensorically improve food (milk, beer, sausage, sauerkraut, pickles, cheese, wine, etc.). Furthermore, SCFAs, like butyric acid, can also double in function as colonocyte fuel and can stimulate gut motility. Needless to say that efficient probiotics should share at least some of these, largely metabolomic, characteristics to be effective in vivo.

\section{Mucosal effects}

Antimicrobial factors are not only made by luminal lactic acid bacteria but also produced by the Paneth cells and secreted in the lumen at the mucosal surface, aiding in host 


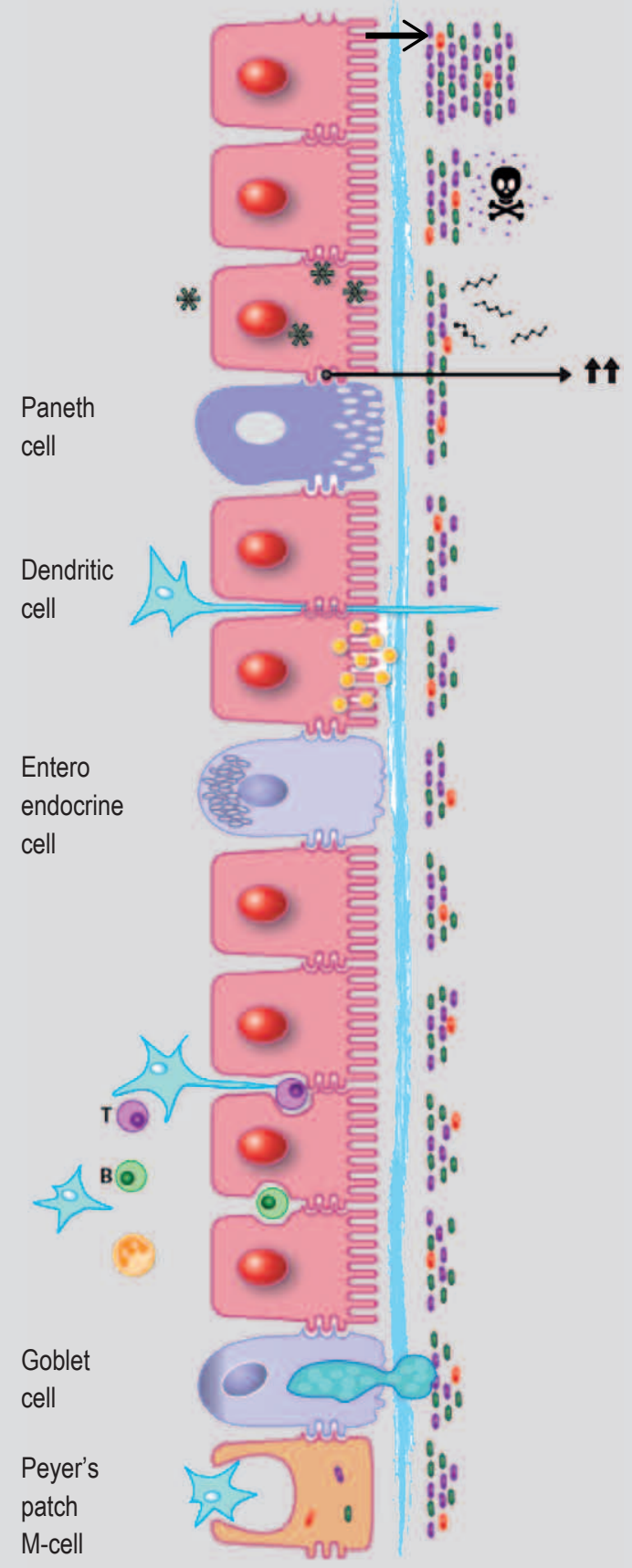

Exclusion by competition for:

- Nutrients

- Space in lumen \& staeric hindrance ( $\rightarrow$ in figure)

- Adherence to gut epithelium

- Quorum sensing effector mechanisms

Bacterial metabolic activity (green asterisks)

- Acids $\downarrow$ pH \& boost beneficial commensals

- Production of bactericides and bacteriostats

- Release of gut stimulators (e.g. butyrate)

- Proteases for hydrolysis of toxins

Preservation of gut-barrier function

- Upregulate synthesis tight junction proteins ( $\uparrow \uparrow$ in figure)

- Decrease macromolecular permeability

- Reduce bacterial translocation

Influence water and ion channels

- Probiotics inhibit secretion, stimulate absorption and upregulate gene expression and transcription of essential transport molecules

Influence nervous system

- Enteroendocrine cells and subepithelial nerves

Modulation of signal transduction

- Block activation \& translocation of IFN-y and transcription factors like NF-kB to nucleus

- Idem for mitogen-activated protein kinases (MAPK)

- Enhance synthesis anti-inflammatory cytokines like IL-10 and TGF- $\beta$

Stimulate innate immune system

- Mucus production (Goblet cells), lysozyme

- MAMPS microbe associated molecular patterns

- Modulate TLR's, RLR's and NLR's

- Trigger Paneth cells to produce alpha-defensins

Initiate and boost adaptive immunity

- Antigen uptake/presenting $M$ \& dendritic cells

- From Peyer's patches to mesenterical lymph nodes

- Immune-cytokines (Th and Tregs)

- $\lg A, \lg G$ and $\lg$ antibodies

- Recirculating memory cells and HEV's

Figure 2. Microbiota, gut mechanisms and cells involved in prevention or reversal of diarrhoea.

IFN = interferon; NFK $\beta=$ nuclear factor kappa beta; IL = interleukin; TGF = transforming growth factor, MAMPS = microbe-associated molecular patterns; TRL = Toll-like receptor; RLR = retinoic acid inducible gene 1 like receptor; $N R L$ = nucleotide oligomerisation domain like receptor; IG = immunoglobulin; HEV = high endothelial venules.

defence by affecting numbers and/or composition of the colonising microbiota. As an integral part of the immediate response innate immune system, Paneth cells produce defensins and other antibiotic peptides and proteins. Because of their juxtaposition to epithelial progenitor (stem) cells at the base of the crypts of Lieberkühn and very high local concentrations of defensins, they are probably involved in maintaining gut renewal. Reduced Paneth cell defensin expression can predispose for pathology, seen in necrotising enterocolitis and ileal Crohn's disease (Salzman et al., 2007).

Probiotics can enhance release of defensins, e.g. as demonstrated in acute infectious enteritis (see Sherman et al., 2009). Trefoil-factors are anti-bacterial peptides that are also secreted by mucin-producing cells in response to various noxious stimuli (Sherman et al., 2009) or 
probiotics (Van Huynegem et al., 2009). The enhanced mucus layer overlying the epithelial lining of the gut serves as an additional antibacterial shield, hampering binding of the pathogens (Sherman et al., 2009). Probiotics, such as Lactobacillus plantarum, can upregulate MUC2 and MUC3 genes, which code for mucus-protein production in humans. Mucus and trefoil factors work in concert with each other and many of the more than twelve hundred (!) antimicrobial peptides nature can call upon for host defence (Nakatsuji and Gallo, 2012). The gut wall exhibits a large degree of luminal chemo-sensitivity sensing a vast array of signals ranging from nutrients, chemicals, mechanical factors and microorganisms (Nguyen, 2012; Raybould, 2012). Entero-endocrine cells are specialised luminal sensors as are sub-epithelial nerve fibres that will respond to those compounds freely diffusing across the epithelium (e.g. SCFAs; Dockray, 2003).

Another direct relation between the nervous system and the gut is the presence, and exquisite sensitivity to probiotics, of opioid and cannabinoid receptors enabling manipulation of visceral perception (including pain; Rousseaux et al., 2007). As described in detail in Table 1, an intimate association between sensing, the nervous system, and ion and water homeostasis exist (Hodges and Gill, 2010). Sensing is also an integral part of the immune system via pattern recognition receptors (PRR) expressed on immune cells like dendritic cells and other tissues like the gut epithelium. PRRs recognise evolutionary conserved molecular structures known as microbe-associated molecular patterns or pathogen-associated molecular patterns and signal effector mechanisms in the innate immune system (Olive, 2012). PRRs can be divided in three families: Toll-like receptors, retinoic acid inducible gene 1 like receptors recognising viruses, and nucleotide oligomerisation domain like receptors. All are three families amenable to modulation by probiotics (Feleszko et al., 2006), excellently reviewed and described in their innate and adaptive immunity context by Wells (2011).

Based on these and other sensing mechanisms, relevant signal transduction pathways (see Figure 2 for NFkappaB and mitogen-activated protein kinase) can be switched on after recognition of pathogens leading to a cascade of events ending in the production of proinflammatory cytokines (as described above, cytokine storm) for defence or anti-inflammatory cytokines when tolerance is needed (Bron et al., 2011; Hodges and Gill., 2010; Sherman et al., 2009; Van Baarlen et al., 2009). Selected probiotic strains and environmental markers of microbial exposure (Ege et al., 2011) can selectively modulate these pathways and enhance or suppress cytokine production switching the immune system between better defence (pathogens, tumour cells) and/or tolerance (to avoid allergy and auto-immunity; Guarner et al., 2006;).
M (microfold) cells, exclusively located over the Peyer's patches, in the gut epithelium continuously sample the lumen for particles like microorganisms, transferring antigens to dendritic cells in the submucosa. Intraepithelial $\mathrm{T}$ and $\mathrm{B}$ lymphocytes produce cytokines $(\mathrm{T})$ and immunoglobulins (B; antibodies) of IgA isotype mainly (Bron et al., 2012). Finally, the gut barrier, formed by only a single layer of epithelial cells, is critically dependent on tight junctions separating the gut lumen from the lamina propria. Bacteria from the microbiota and probiotics alike target the tight junction proteins and thereby modulate the barrier and thus permeability (Ulluwishewa et al., 2011).

\section{Submucosal effects}

The 'business end' of the gut immune system is mainly present in the lumen as sIgA immunoglobulin in the mucus layer on top of the epithelial cells and as intraepithelial lymphocytes. However, the actual initiation of the immune response takes place in the Peyers's patches, large lymphocyte follicles in the submucosa. After the antigens are presented (by dendritic cells in villi or through M cells) and $\mathrm{T}$ and $\mathrm{B}$ cells are recruited the actual immune response is started in the draining mesenterical lymph nodes from where the activated $\mathrm{T}$ and $\mathrm{B}$ cells are transported back to the villi via the blood vessels (Brandtzaeg and Pabst, 2004; Bron et al., 2012). This seemingly elaborate mechanism ensures that the villi have more room for their primary function, uptake of nutrients and water, and that specific immune effector-cells can be initiated at one single site (after pathogen recognition) and then be evenly redistributed over the entire length of the gut, thereby providing uniform specific protection and memory. The entire process is critically controlled by dendritic cells and effector-cells are always under control of $\mathrm{T}$ regulator cells, ensuring not only a decent start of the specific response but also, and maybe more importantly, a timely end to the response (Wells, 2011) avoiding self-inflicted pathology (Chinen and Rudensky, 2012; Van Driel and Ang, 2008).

\section{Clinical use of probiotics}

With over 700 clinical trials in healthy volunteers and patients one might conclude that probiotics have come of age and their use is as evident as the mechanisms they modulate such as described above. Unfortunately, effects of probiotics are always dose and strain specific making comparison of clinical results with different preparations very difficult. In an effort to at least indicate in which areas probiotics can be recommended on scientific grounds, Floch et al. (2011) made an update of existing data. In their analysis they listed evidence as: 'A = strong positive studies in literature, ' $\mathrm{B}=$ positive-controlled studies, but some negative studies not supporting the primary outcome' and ' $\mathrm{C}=$ some positive studies, but not enough for certainty'. They concluded that A claims can only be 
given for infectious diarrhoea in children, antibioticassociated diarrhoea (AAD), pouchitis, ulcerative colitis (maintenance), immune response and atopic eczema. In most of these clinical indications a combination of probiotic strains instead of a monospecific single strain was used (Chapman et al., 2011).

\section{Clinical use of probiotics in Clostridium difficile infection}

In the studies by Floch et al. (2011), prevention of (recurrent) C. difficile associated diarrhoea was given a disappointing $\mathrm{B} / \mathrm{C}$ marking and only one bacterial product with one strain (Lactobacillus rhamnosus GG; ATCC 53103) was included. Consequently, even with a substantial number of studies (Malaguarnera et al., 2012) and very positive metaanalysis showing probiotics are associated with a reduction in AAD (Hempel et al., 2012; Videlock and Cremoni, 2012), a reliable probiotic formulation for CDI has still to be clinically (significance in intent-to-treat) proven. Still a positive attitude towards the future success of anti-CDI probiotics can be seen and specific recommendations for use are given (Hickson, 2011). Single strain versus multistrain preparations are still discussed controversially (Chapman et al., 2011). There is some evidence for single strain applications, such as non-toxigenic $C$. difficile strains, for treatment (Phase 2 studies) based on the idea of a monoclonal pathogenesis of toxigenic C. difficile (Hell et al.2011). But a number of factors have to be taken into account when developing a new probiotic formulation in this field, these being: age of the host, optimal dose, stability, safety, mucosal adherence, gastric acid and bile resistance, matrix of delivery, specific strains, interaction within combination products and optimal duration of treatment (Verna and Lucak, 2010). The high efficiency of faecal microbiota transplantation is a fundamental fact that can be relied on in probiotic CDI treatment (Brandt., 2012; Tschuddin-Sutter et al., 2012). Based on this, a recent metanalysis by Johnston et al., 2012) and the fact that C. difficile has unique necro-inflammatory pathogenesis, as described in detail in Section 2, we postulate that only a multistrain cocktail (resembling a 'healthy' human microbiota) could come close to addressing all mechanistical needs (Figure 2 and Table 1 ) in the CDI setting.

\section{Design and methods of a clinical study}

For the reasons listed in the previous section a product (Ecologic ${ }^{\circ} \mathrm{AAD}$, Winclove Bio Industries BV, Amsterdam, the Netherlands) was assembled consisting of equal ratios of the following 10 bacterial strains with a total dose of 5 $\mathrm{g} / \mathrm{sachet}$ and of $10^{9} \mathrm{cfu} / \mathrm{g}$ : Bifidobacterium bifidum W23, Bifidobacterium lactis W18, Bifidobacterium longum W51, Enterococcus faecium W 54, Lactobacillus acidophilus W37 and W55, Lactobacillus paracasei W20, L. plantarum W62, L. rhamnosus W71, Lactobacillus salivarius W24 and a mixture of $5 \%$ mineral elements, in Austria branded as $\left.\mathrm{OMNiBiOTiC}^{\oplus} 10 \mathrm{AAD}\right)$ ).

\section{Case definition}

A patient was identified as a laboratory confirmed, symptomatic CDI patient who received adjunctive probiotic therapy at the time when oral metronidazol or vancomycin was initiated. Participants consumed sachets containing $5 \mathrm{~g}$ Ecologic ${ }^{\circ} \mathrm{AAD}$ twice daily. Patients were studied by queering surveillance data, consecutively followed by interviewing staff by phone. Retrospectively, medical records were reviewed to ascertain clinical signs of CDI, therapy, medical history and outcome.

Severe CDI was defined by clinical signs of severe colitis and laboratory findings confirming a severe course; recurrent CDI was defined as described by Bauer et al. (2009). The decision to initiate adjunctive probiotic therapy was made by the individual attending physician in cooperation with an infectious diseases consultant. On the basis of retrospective chart review all patients met the following criteria: diarrhoea, antibiotic treatment with metronidazole or vancomycin and multistrain probiotics.

\section{Clinical setting and inclusion criteria}

A 1,200 bed, tertiary care, university hospital (five different clinical departments) participated during the period from 1 November 2010 to 31 July 2011. After laboratory proof of C. difficile (toxigenic culture), a standardised interview was carried out for each patient, asking for date and reason of admission, clinical symptoms, onset of clinical symptoms, underlying diseases, comorbities and antibiotic history. If the patient was selected for the study, patients' records were searched for antibiotic history, additional medication like PPIs and cortison, fever, leukocyte counts, C-reactive protein (CRP), radiology and endoscopy results. A followup was done after six month.

\section{Treatment description and definition of resolution}

To test whether the product was actually performing and no strain to strain inhibitory effects were introduced by combining so many strains, a pilot study including a series of ten elderly patients, complemented by a detailed chart review, was performed. Resolution was defined as no further laboratory signs of inflammation and/or fever, and reduction of stool frequency less than 3 times $/ 24 \mathrm{~h}$ for at least $72 \mathrm{~h}$ according to Bauer et al. (2009).

All patients received oral vancomycin $125 \mathrm{mg}$ qid for at least 10 days, 8 patients received additionally oral metronidazole $500 \mathrm{mg}$ tid, 4 patients got a combination of oral vancomycin and iv treatment with metronidazole, and 9 were still under concomitant iv treatment with other antibiotics because of their underlying disease. 
A complementary epidemiological investigation was done outside the hospital CDI surveillance system for both the period of the investigated cases and for the time period 2009-2011 (Table 2) to gain more background information of the local/hospital epidemiological situation.

\section{Results of a clinical study}

Table 2 clearly shows that the caseload of CDI is proportionally much higher in the group under 70 years of age, with 521 cases under 70 years of age versus 452 in the group over 70. In absolute numbers, the proportion of $C$. difficile fatal cases (causative and contributive cases) was $21(<70)$ over $29(>70)$, but in a relative way this was $4 \%$ over $6.5 \%$ or a $63 \%$ increase in the $>70$ age bracket. No differences could be seen per 5 year age bracket $>70$. This clearly shows that the Salzburg cohort behaves as described in the literature (reviewed in Islam et al., 2012): relatively more CDI in older people and absolutely (and relatively) more deaths contributed to or caused by $C$. difficile in $>70$ years. From this base line situation we selected the cases.

\section{Patients characteristics, risk factors, and clinical presentation}

The demographic characteristics, comorbidities, and clinical presentations of all patients are listed in Table 3 . The mean age of the patients was 82 years (range 72 89 ); the majority were men (7 out of 10 ). All patients were hospitalised at the onset of CDI. Only one out of the 10 patients had no history of antimicrobials; 9 of 10 received antimicrobial medication (range 1 to 6 , mean 3.7 different antibiotics) in the last three months before onset of CDI. The most frequently administered antibiotics were ciprofloxacin and amoxicillin+clavulanic acid (each 5 out of 9 patients) and piperacillin+tazobactam (4 out of 9 patients). 8 patients got PPIs and/or cortison before and during the CDI-therapy. 4 out of 10 patients had received different single-strain probiotics before. All but one patient suffered from severe underlying diseases like malignancies, renal failure or chronic vascular diseases. 6 of 10 patients showed fever (defined as body temperature $\geq 38^{\circ} \mathrm{C}$ at the time the stool samples were taken). Mean leukocyte count was 13,500 (range 4,200 to 25,500 ) and mean CRP was $13.7 \mathrm{~g} / \mathrm{dl}$ (range 3 to $26.2 \mathrm{~g} / \mathrm{dl}$ ).

\section{Laboratory and radiography results}

In all patients, CDI had been confirmed by laboratory results (stool culture for $C$. difficile and toxin A- and B-positive ELISA test) before they were included in the survey. Radiography and endoscopy brought no further useful information: in 3 cases abdominal X-rays were done but without description of the colon; in one case an abdominal CT scan was performed, but, as the patient was already known for chronic radiogenic colitis, there was no valid information about CDI. In 2 out of 10 cases endoscopy was initiated. One showed no sign of enteritis, the other was aborted because of bleeding and stenosis.

\section{Case reports}

From the 10 patients who received adjunctive probiotic therapy 3 patients were selected to represent our case series population; these patients are discussed below. The demographic characteristics, comorbidities, and clinical presentations of all patients are listed in Tables 3 and 4 . None of this three cases experienced a relapse for more than six months, however, as described below, one of them (patient 1) had already been treated with a multistrain probiotic for a short time period before and had a relapse two weeks later.

\section{Patient 1 (Case 3 in Tables 3 and 4)}

A 72 year-old male with tuberculosis, recurrent glomerulonephritis, and urinary tract infection (UTI) (due to extended spectrum $\beta$-lactamase producing Escherichia coli) who had been treated with hydrocortison and several antibiotics (ciprofloxacin, rifampicin, amoxicillin+clavulanic acid and sulfonamide+trimethoprim) for six months was admitted to our hospital with the second relapse of CDI. He tested positive for $C$. difficile (ribotype 413) in the stool specimen taken at admission. After an initial treatment with metronidazole he was treated with vancomycin and a multistrain probiotic. Three days later, the patient experienced full clinical resolution. Even after further treatment with ciprofloxacin and pivmecillinam for more than a month, no CDI-relapse occurred.

Table 2. Population characteristics of Clostridium difficile infection cases at University Hospital Salzburg from 2009 to 2011.

$\begin{array}{lcccccc}\text { Age group } & \text { Survived } & \text { Died } & \text { Causative } & \text { Contributive } & \text { Inconclusive } & \% \text { causative + contributive } \\ <70 \text { years } & 479 & 42 & 6 & 15 & 21 & 4.0 \\ 70-74 \text { years } & 103 & 16 & 2 & 6 & 8 & 6.7 \\ 75-79 \text { years } & 88 & 13 & 1 & 6 & 6 & 6.9 \\ >80 \text { years } & 209 & 23 & 3 & 11 & 9 & 6.0\end{array}$


Table 3. Demographic characteristics, underlying disease, manifestation of Clostridium difficile infection (CDI) (primary episode, first or second relapse) and risk factors.

\begin{tabular}{|c|c|c|c|c|c|c|c|c|}
\hline 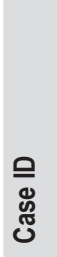 & 丒 & ふ & Underlying disease & 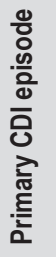 & 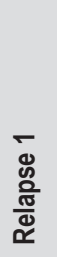 & 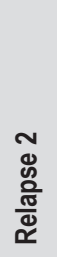 & Antimicrobials history & 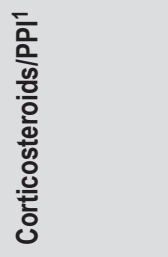 \\
\hline 1 & 88 & $\mathrm{~m}$ & CDI & & $x$ & & None & PPI \\
\hline 2 & 89 & $f$ & uterus carcinoma & $\mathrm{x}$ & & & Unknown antibiotic, Ciprofloxacin & None \\
\hline 3 & 72 & $\mathrm{~m}$ & glomerulonephritis & & & $x$ & Ciprofloxacin, AmoxClav, Rifampicin, SulfTrim & Cortison \\
\hline 4 & 85 & f & epilepsia & $\mathrm{x}$ & & & Cefazolin, PipTaz & PPI \\
\hline 5 & 85 & m & bladder carcinoma & & & $x$ & $\begin{array}{l}\text { Ciprofloxacin, PipTaz, Ceftriaxon, SulfTrim, } \\
\text { Vancomycin, AmoxClav }\end{array}$ & PPI \\
\hline 6 & 80 & $\mathrm{~m}$ & bronchitis, recurrent urinary tract infection & $x$ & & & Ciprofloxacin, Levofloxacin, SulfTrim & PPI \\
\hline 7 & 76 & $\mathrm{~m}$ & renal replacement therapy & $\mathrm{x}$ & & & Ciprofloxacin, AmoxiClav, PipTaz & Cortison, PPI \\
\hline 8 & 79 & $\mathrm{~m}$ & endocarditis, CDI & & $\mathrm{x}$ & & Clarithromycin, Moxifloxacin, Metronidazole & Cortison, PPI \\
\hline 9 & 81 & $\mathrm{~m}$ & peripheral arterial occlusive disease & $\mathrm{x}$ & & & $\begin{array}{l}\text { AmoxClav, Clarithromycin, Clindamycin, } \\
\text { Ciprofloxacin, PipTaz }\end{array}$ & None \\
\hline 10 & 85 & f & sepsis, recurrent erysipelas, recurrent CDI & & $\mathrm{x}$ & & $\begin{array}{l}\text { AmoxClav, Meropenem, Metronidazole, } \\
\text { Vancomycin, AmpSulbactam }\end{array}$ & PPI \\
\hline
\end{tabular}

Table 4. Treatment, laboratory findings and outcomes of Clostridium difficile infection cases. ${ }^{1,2}$

\begin{tabular}{|c|c|c|c|c|c|c|c|c|c|c|c|}
\hline 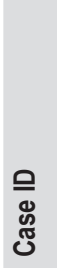 & 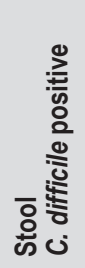 & 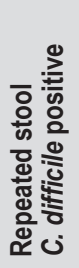 & 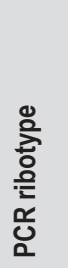 & $\frac{N}{\Sigma}$ & 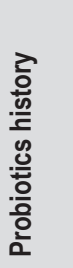 & 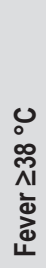 & Radiography ${ }^{3}$ & Endoscopy & 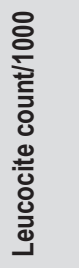 & $\begin{array}{l}\bar{y} \\
\text { o } \\
\text { 옹 }\end{array}$ & 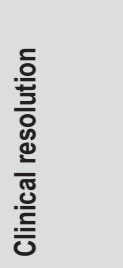 \\
\hline 1 & Y & $\mathrm{N}$ & 023 & Y & SSP & Y & $\mathrm{N}$ & $\mathrm{N}$ & 17.7 & 3 & complete $^{4}$ \\
\hline 2 & Y & N & 014 & $\mathrm{~N}$ & $\mathrm{~N}$ & $\mathrm{~N}$ & $\mathrm{Y}$, colon not described & $\mathrm{N}$ & 8.98 & 6.4 & complete \\
\hline 3 & Y & $\mathrm{N}$ & 413 & Y & $\mathrm{N}$ & Y & Y, colon not described & $\mathrm{N}$ & 4.2 & 8 & complete \\
\hline 4 & Y & $\mathrm{N}$ & 433 & Y & SSP & Y & $\mathrm{N}$ & $\mathrm{N}$ & 12.66 & 15.1 & complete \\
\hline 5 & Y & $\mathrm{N}$ & 014 & Y & MSP & Y & $\begin{array}{l}\text { Y, CT: known radiogenic } \\
\text { colitis }\end{array}$ & $\begin{array}{l}\text { Y, aborted, bleeding and } \\
\text { stenosis }\end{array}$ & 11.4 & 20.3 & complete \\
\hline 6 & Y & $\mathrm{N}$ & nd & Y & SSP & $\mathrm{N}$ & Y, colon not described & $\mathrm{Y}$, no sign of enteritis & 10.46 & 6.8 & complete \\
\hline 7 & Y & $\mathrm{N}$ & nd & Y & $\mathrm{N}$ & $\mathrm{N}$ & $\mathrm{N}$ & $\mathrm{N}$ & 12.11 & 16.86 & complete \\
\hline 8 & Y & N & 053 & N & $\mathrm{N}$ & $\mathrm{N}$ & $\mathrm{N}$ & $\mathrm{N}$ & 18.52 & 13.2 & complete \\
\hline 9 & Y & $\mathrm{N}$ & nd & Y & SSP & $Y$ & N & $\mathrm{N}$ & 25.48 & 26.2 & complete \\
\hline 10 & Y & nd & 053 & Y & MSP & $Y$ & $\mathrm{~N}$ & $\mathrm{~N}$ & 13.45 & 20.9 & complete \\
\hline
\end{tabular}

\footnotetext{
${ }^{1}$ All patients received four times an oral dosage $125 \mathrm{mg}$ vancomycin and twice daily a multistrain probiotic.

${ }^{2}$ Abbreviations used: $\mathrm{CRP}=\mathrm{C}$-reactive protein; $\mathrm{MSP}=$ multistrain probiotic; $\mathrm{MTZ}=$ metronidazole; $\mathrm{N}=$ no; $\mathrm{nd}$ = not done; $\mathrm{SSP}=$ single strain probiotic; $Y=$ yes.

${ }^{3}$ Radiography with plain film, CT or sonography.

${ }^{4}$ Patient died of pneumonia three months later.
} 
Patient 2 (Case 5 in Tables 3 and 4)

An 85 year-old male was admitted to our hospital with a known bladder carcinoma and recurrent CDI with diarrhoea. He had already been tested positive for $C$. difficile in stool specimens one month before, after he had received ceftriaxon, and tested positive again in the stool specimen taken at admission (ribotype 014). The first CDI episode was treated with vancomycin and a multistrain probiotic. The latter was prescribed for sixteen days, however, the patient was discharged from the hospital at day three. At readmission, he was treated first with metronidazole for five days; after consulting an infectious disease specialist, the therapy was switched to vancomycin, combined with a multistrain probiotic anew. Three days later, the patient experienced full clinical resolution.

\section{Patient 3 (Case 8 in Tables 3 and 4)}

A 79 year-old male who underwent transcutaneous aortic valve replacement developed endocarditis and was treated with clindamycin and ceftriaxon for one week, then followed by imipenem and moxifloxacin for 2 weeks. No diarrhoea was documented during this period nor stool samples were taken. One month later, after continously receiving moxifloxacin, he was readmitted with CDI, reporting diarrhoea at home for already two weeks. He tested positive for C. difficile (ribotype 053) in the stool specimen taken at admission and was treated with vancomycin and a multistrain probiotic. Five days later, the patient experienced full clinical resolution.

\section{Treatment and outcomes}

All patients under survey received $4 \times 125 \mathrm{mg}$ oral vancomycin and $2 \times$ the multistrain probiotic. Five patients suffered from recurrent CDI. Complete resolution of clinical presentation occurred in 9 patients (90\%), and one of the observed subjects died within a 3-months follow-up period from pneumonia, apparently without a connection to the CDI episodes. No adverse events were reported. A repeated stool testing was performed in 9 out of 10 patients and these proofed to be negative. Molecular characterisation of the strains was done in $70 \%$ (7 out of 10); PCR-ribotyping revealed thereby 5 different strains $(2 \times 014,2 \times 053$ and one of each $023,433,413$ ) (Table 4). No clustering or transmission was seen among the investigated patients.

Data from our surveillance system indicated 9 fatal courses directly related to CDI out of 151 cases (case-fatality ratio $6 \%$ ) during the observation period. 84 of the observed patients were males; the mean age was 67 (range 19-94). None of the fatal cases had a documented treatment with probiotics.

\section{Discussion}

Stool microbiota is best understood as a complex, living, interdependent ecosystem. During periods of health, bacterial gut residents suppress growth of $C$. difficile in the colon. Broad-spectrum antimicrobials have the potential to disrupt the balanced ecology of the stool microbiota, creating an opportunity for $C$. difficile spores to germinate resulting in overgrowth and attendant production of toxins, which are responsible for most of the clinical symptoms of CDI and (pseudomembraneous)-colitis. Antibiotics like clindamycin are known to impair colonisation resistance, however, second- and third-generation cephalosporins (for which all clinical isolates of $C$. difficile are resistant) and fluoroquinolones are frequently used in hospital infections/ patients and cause iatrogenic CDI (Kelly, 2009). Patients can keep shedding (bacteria, toxins and spores) for some weeks despite full clinical recovery. Those asymptomatic carriers emphasise the need for transmission reduction and universal infection control measures. Using gloves for avoiding direct skin contact and hand hygiene with plain soap and running water to remove spores followed by an alcoholic hand rub is preferred over alcohol-based hand rubs alone for symptomatic patients or patients with a recent known CDI-episode. To reduce the environmental burden, spores should be removed with sporicidal agents (chlorine) on surfaces adjacent to the patients, as well as for toilets and showers (Kelly 2009). Detergents based on peroxides or glutaraldehyde are also effective (TschudinSutter, 2012). The fundamental problem in CDI is not the presence of the pathogenic organism per se, but the absence of healthy microbiota to keep the growth of the pathogen suppressed. Accordingly, one would anticipate that the restoration of bacterial homeostasis in the colon could resolve diarrhoea states caused by uncontrolled growth of C. difficile.

C. difficile is a leading cause of AAD. The severity of CDI ranges from mild cases, which require little more than the discontinuation of antimicrobials to intractable diarrhoea, to relapsing infection and severe life-threatening illness. Mortality/fatality rates as high as $26 \%$ have been reported in old and very old patients, and patients with underlying disease like progressive solid tumours. Especially haematology-oncology patients, having systemic diseases and receiving high dose chemotherapy, are at risk for CDI (Hautmann et al., 2011). Both the recurrence and overgrowth after initial dysbiosis can be partly explained by spore forming ability, specific adhesions in the colon and hypervirulent strains via additional production of a binary toxin. The cost per case ranges from approx. 2,500 USD (total cost estimate 3.5 billion) to 4,000 USD in the UK (Hickson, 2011), with health care system costs between 5,000 (USA) and 8,000 (EU) USD per primary episode and almost 14,000 USD for a case of recurrent CDI (Hautmann et al., 2011) with a total burden worldwide in the tens of 
billions. All available data show that CDI is much more difficult to prevent and cure than ordinary diarrhoea. In addition, the spore forming ability results in enormous recurrence rates.

Recent meta-analysis on CDI treatment successes (Johnston et al., 2012) in faecal transplantation in CDI therapy (Brandt, 2012; Van Nood et al., 2013) and this case series shows that even in patients at high risk, with multiple severe underlying diseases, administration of multistrain probiotics might be beneficial by shortening the diseases course as well as by preventing further relapses in patients with recurrent CDI. Furthermore, this paper presents a theoretical and practical basis to initiate well-designed clinical trials (Morrow et al., 2012) to evaluate multistrain probiotic treatment in CDI patient groups with different underlying diseases.

\section{Acknowledgements}

We would like to thank the heads of the different clinical departments at the University Hospital Salzburg, Paracelsus Medical University for their support with clinical data. The authors wish to thank Joop van Orsouw for preparing the figures and Saskia van Hemert (Winclove) for guidance. No financial conflicts of interest are declared for this study.

\section{References}

Bauer, M.P. and Van Dissel, J.T., 2009. Alternative strategies for Clostridium difficile infection. International Journal of Antimicrobial Agents 33: S51-S56.

Bauer, M.P., Kuijper, E.J., Van Dissel, J.T. and European Society of Clinical Microbiology and Infectious Diseases, 2009. European Society of Clinical Microbiology and Infectious Diseases (ESCMID): treatment guidance document for Clostridium difficile infection (CDI). Clinical Microbiology and Infection 15: 1067-1079.

Borthakur, A., Gill, R.K., Tyagi, S., Koutsouris, A., Alrefai, W.A., Hecht, G.A., Ramaswamy, K. and Dudeja, P.K., 2008. The probiotic Lactobacillus acidophilus stimulates chloride/hydroxyl exchange activity in human intestinal epithelial cells. Journal of Nutrition 138: 1355-1359.

Brandt, L.J., 2012. Fecal transplantation for the treatment of Clostridium difficile infection. Gastroenterology and Hepatology of CNY 8: 191-194.

Brandtzaeg, P. and Pabst, R., 2004. Let's go mucosal: communication on slippery ground. Trends in Immunology 25: 570-577.

Bron, P.,A., Van Baarlen, P. and Kleerebezem, M., 2012. Emerging molecular insights into the interaction between probiotics and the host intestinal mucosa. Nature Reviews Microbiology 10: 66-78.

Cadieux, P.A., Burton, J., Devillard, E. and Reid, G., 2009. Lactobacillus by-products inhibit the growth and virulence of uropathogenic Escherichia coli. Journal of Physiology and Pharmacology 60 Suppl. 6: 13-18.

Cartman, S.T., Heap, J.T., Kuehne, S.A., Cockayne, A. and Minton, N.P., 2010. The emergence of 'hypervirulence' in Clostridium difficile. International Journal of Medical Microbiology 300: 387-395.
Chapman, C.M., Gibson, G.R. and Rowland, I., 2011. Health benefits of probiotics: are mixtures more effective than single strains? European Journal of Nutrition 50:1-17.

Chinen, T. and Rudensky, A.Y., 2012. The effects of commensal microbiota on immune cell subsets and inflammatory responses. Immunological Reviews 245: 45-55.

Cohen, S.H., Gerding, D.N., Johnson, S., Kelly, C.P., Loo, V.G., McDonald, L.C., Pepin, J., Wilcox, M.H., the Society for Healthcare Epidemiology of America and the Infectious Diseases Society of America, 2010. Clinical practice guidelines for Clostridium difficile infection in adults: 2010 update by the Society for Healthcare Epidemiology of America (SHEA) and the Infectious Diseases Society of America (IDSA). Infection Control and Hospital Epidemiology 31: 431-455.

De Vuyst, L., Vrancken, G., Ravyts, F., Rimaux, T. and Weckx, S., 2009. Biodiversity, ecological determinants, and metabolic exploitation of sourdough microbiota. Food Microbiology 26: 666-675.

Dean, P., Maresca, M., Schuller, S., Phillips, A.D. and Kenny, B., 2006. Potent diarrheagenic mechanism mediated by the cooperative action of three enteropathogenic Escherichia coli-injected effector proteins. Proceedings of the National Academy of Sciences of the USA 103: 1876-1881.

Dockray, G.J., 2003. Luminal sensing in the gut: an overview. Journal of Physiology and Pharmacology 54 Suppl. 4: 9-17.

Ege, M.J., Mayer, M., Normand, A.C., Genuneit, J., Cookson, W.O., Braun-Fahrlander, C., Heederik, D., Piarroux, R. and Von Mutius, E. for the GABRIELA Transregio 22 Study Group, 2011. Exposure to environmental microorganisms and childhood asthma. New England Journal of Medicine 364: 701-709.

Feleszko, W., Jaworska, J. and Hamelmann, E., 2006. Toll-like receptors - novel targets in allergic airway disease (probiotics, friends and relatives). European Journal of Pharmacology 533: 308-318.

Floch, M.H., Walker, W.A., Madsen, K., Sanders, M.E., Macfarlane, G.T., Flint, H.J., Dieleman, L.A., Ringel, Y., Guandalini, S., Kelly, C.P. and Brandt, L.J., 2011. Recommendations for probiotic use - 2011 update. Journal of Clinical Gastroenterology 45 Suppl.: S168-S171.

Guarner, F., Bourdet-Sicard, R., Brandtzaeg, P., Gill, H.S., McGuirk, P., Van Eden, W., Versalovic, J., Weinstock, J.V. and Rook, G.A., 2006. Mechanisms of disease: the hygiene hypothesis revisited. Nature Clinical Practice: Gastroenterology \& Hepatology 3: 275-284.

Hall, I.C. and O'Toole, E., 1935. Intestinal flora in new-born infants: with a description of a new pathogenic anaerobe, Bacillus difficile. American Journal of Diseases in Childhood 49: 390-402.

Hautmann, M.G., Hipp, M. and Kolbl, O., 2011. Clostridium difficileassociated diarrhea in radiooncology: an underestimated problem for the feasibility of the radiooncological treatment? Radiation Oncology 6: 89.

Hayashi, H., Szaszi, K., Coady-Osberg, N., Furuya, W., Bretscher, A.P., Orlowski, J. and Grinstein, S., 2004. Inhibition and redistribution of $\mathrm{NHE} 3$, the apical $\mathrm{Na}+\mathrm{H}+$ exchanger, by Clostridium difficile toxin B. Journal of General Physiology 123: 491-504.

Hell, M., Permoser, M., Chmelizek, G., Kern, J.M., Maass, M., Huhulescu, S., Indra, A. and Allerberger, F., 2011. Clostridium difficile infection: monoclonal or polyclonal genesis? Infection 39: 461-465. 
Hell, M., Sickau, K., Chmelizek, G., Kern, J.M., Maass, M., Huhulescu, S. and Allerberger, F., 2012. Absence of Clostridium difficile in asymptomatic hospital staff. American Journal of Infection Control 40: 1023-1024.

Hempel, S., Newberry, S.J., Maher, A.R., Wang, Z., Miles, J.N., Shanman, R., Johnsen, B. and Shekelle, P.G., 2012. Probiotics for the prevention and treatment of antibiotic-associated diarrhea: a systematic review and meta-analysis. Journal of the American Medical Association 307: 1959-1969.

Heuvelin, E., Lebreton, C., Bichara, M., Cerf-Bensussan, N. and Heyman, M., 2010. A Bifidobacterium probiotic strain and its soluble factors alleviate chloride secretion by human intestinal epithelial cells. Journal of Nutrition 140: 7-11.

Hickson, M., 2011. Probiotics in the prevention of antibiotic-associated diarrhoea and Clostridium difficile infection. Therapeutic Advances in Gastroenterology 4: 185-197.

Hodges, K. and Gill, R., 2010. Infectious diarrhea: cellular and molecular mechanisms. Gut Microbes 1: 4-21.

Ishihara, E., Nagahama, M., Naruse, S., Semba, R., Miura, T., Usami, M. and Narita, M., 2008. Neuropathological alteration of aquaporin 1 immunoreactive enteric neurons in the streptozotocin-induced diabetic rats. Autonomic Neuroscience 138: 31-40.

Islam, J., Cohen, J., Rajkumar, C. and Llewelyn, M.J., 2012. Probiotics for the prevention and treatment of Clostridium difficile in older patients. Age and Ageing 41: 706-711.

Johnston, B.C., Ma, S.S., Goldenberg, J.Z., Thorlund, K., Vandvik, P.O., Loeb, M. and Guyatt, G.H., 2012. Probiotics for the prevention of Clostridium difficile-associated diarrhea: a systematic review and meta-analysis. Annals of Internal Medicine 157: 878-888.

Karczewski, J., Troost, F.J., Konings, I., Dekker, J., Kleerebezem, M., Brummer, R.J. and Wells, J.M., 2010. Regulation of human epithelial tight junction proteins by Lactobacillus plantarum in vivo and protective effects on the epithelial barrier. American Journal of Physiology - Gastrointestinal and Liver Physiology 298: G851-859.

Kelly, C.P., 2009. A 76-year-old man with recurrent Clostridium difficile-associated diarrhea: review of C. difficile infection. Journal of the American Medical Association 301: 954-962.

Kelly, G., 2008. Inulin-type prebiotics - a review: part 1. Alternative Medicine Review 13: 315-329.

Kyne, L., Warny, M., Qamar, A. and Kelly, C.P., 2000. Asymptomatic carriage of Clostridium difficile and serum levels of IgG antibody against toxin A. New England Journal of Medicine 342: 390-397.

Louie, T.J., Cannon, K., Byrne, B., Emery, J., Ward, L., Eyben, M. and Krulicki, W., 2012. Fidaxomicin preserves the intestinal microbiome during and after treatment of Clostridium difficile infection (CDI) and reduces both toxin reexpression and recurrence of CDI. Clinical Infectious Diseases 55 Suppl. 2: S132-142.

Malaguarnera, G., Leggio, F., Vacante, M., Motta, M., Giordano, M., Bondi, A., Basile, F., Mastrojeni, S., Mistretta, A., Malaguarnera, M., Toscano, M.A. and Salmeri, M., 2012. Probiotics in the gastrointestinal diseases of the elderly. The Journal of Nutrition, Health and Aging 16: 402-410.

Malakooti, J., Saksena, S., Gill, R.K. and Dudeja, P.K., 2011. Transcriptional regulation of the intestinal luminal $\mathrm{Na}(+)$ and $\mathrm{Cl}(-)$ transporters. Biochemical Journal 435: 313-325.
McFarland, L.V., 2011. Emerging therapies for Clostridium difficile infections. Expert Opinion in Emerging Drugs 16: 425-439.

Mercenier, A., Muller-Alouf, H. and Grangette, C., 2000. Lactic acid bacteria as live vaccines. Current Issues in Molecular Biology 2: 17-25.

Morishima, T., Aoyama, M., Iida, Y., Yamamoto, N., Hirate, H., Arima, H., Fujita, Y., Sasano, H., Tsuda, T., Katsuya, H., Asai, K. and Sobue, K., 2008. Lactic acid increases aquaporin 4 expression on the cell membrane of cultured rat astrocytes. Neuroscience Research 61: 18-26.

Morrow, L.E., Gogineni, V. and Malesker, M.A., 2012. Probiotic, prebiotic, and symbiotic use in critically ill patients. Current Opinion in Critical Care 18: 186-191.

Moudgal, V. and Sobel, J.D., 2012. Clostridium difficile colitis: a review. Hospital Practice 40: 139-148.

Nakatsuji, T. and Gallo, R.L., 2012. Antimicrobial peptides: old molecules with new ideas. Journal of Investigative Dermatology 132: 887-895.

Nguyen, C.A., Akiba, Y. and Kaunitz, J.D., 2012. Recent advances in gut nutrient chemosensing. Current Medicinal Chemistry 19: 28-34.

Ohland, C.L., DeVinney, R. and MacNaughton, W.K., 2012. Escherichia coli-induced epithelial hyporesponsiveness to secretagogues is associated with altered CFTR localization. Cellular Microbiology 14: 447-459.

Olive, C., 2012. Pattern recognition receptors: sentinels in innate immunity and targets of new vaccine adjuvants. Expert Review of Vaccines 11: 237-256.

Parkes, G.C., Sanderson, J.D. and Whelan, K., 2009. The mechanisms and efficacy of probiotics in the prevention of Clostridium difficileassociated diarrhoea. Lancet Infectious Diseases 9: 237-244.

Rousseaux, C., Thuru, X., Gelot, A., Barnich, N., Neut, C., Dubuquoy, L., Dubuquoy, C., Merour, E., Geboes, K., Chamaillard, M., Ouwehand, A., Leyer, G., Carcano, D., Colombel, J.F., Ardid, D. and Desreumaux, P., 2007. Lactobacillus acidophilus modulates intestinal pain and induces opioid and cannabinoid receptors. Nature Medicine 13: 35-37.

Saadoun, S. and Papadopoulos, M.C., 2010. Aquaporin-4 in brain and spinal cord oedema. Neuroscience 168: 1036-1046.

Salzman, N.H., Underwood, M.A. and Bevins, C.L., 2007. Paneth cells, defensins, and the commensal microbiotal: a hypothesis on intimate interplay at the intestinal mucosa. Seminars in Immunology 19: 70-83.

Sherman, P.M., Ossa, J.C. and Johnson-Henry, K., 2009. Unraveling mechanisms of action of probiotics. Nutrition in Clinical Practice 24: $10-14$.

Singla, A., Kumar, A., Priyamvada, S., Tahniyath, M., Saksena, S., Gill, R.K., Alrefai, W.A. and Dudeja, P.K., 2012. LPA stimulates intestinal DRA gene transcription via LPA2 receptor, PI3K/AKT, and c-Fos-dependent pathway. American Journal of Physiology -Gastrointestinal and Liver Physiology 302: G618-G627.

Swartz, T.D., Duca, F.A., De Wouters, T., Sakar, Y. and Covasa, M., 2012. Up-regulation of intestinal type 1 taste receptor 3 and sodium glucose luminal transporter-1 expression and increased sucrose intake in mice lacking gut microbiota. British Journal of Nutrition 107: 621-630. 
Tschudin-Sutter, S., Widmer, A.F. and Perl, T.M., 2012. Clostridium difficile: novel insights on an incessantly challenging disease. Current Opinion in Infectious Diseases 25: 405-411.

Ulluwishewa, D., Anderson, R.C., McNabb, W.C., Moughan, P.J., Wells, J.M. and Roy, N.C., 2011. Regulation of tight junction permeability by intestinal bacteria and dietary components. Journal of Nutrition 141: 769-776.

Van Baarlen, P., Troost, F., Van der Meer, C., Hooiveld, G., Boekschoten, M., Brummer, R.J.M. and Kleerebezem, M., 2011. Human mucosal in vivo transcriptome responses to three lactobacilli indicate how probiotics may modulate human cellular pathways. Proceedings of the National Academy of Sciences of the USA 108 Suppl. 1: 4562-4569.

Van Baarlen, P., Troost, F., Van Hemert, S., Van der Meer, C., De Vos, W.M., De Groot, P.J., Hooiveld, G.J.E.J., Brummer, R.J.M. and Kleerebezem, M., 2009. Differential NF-kappaB pathways induction by Lactobacillus plantarum in the duodenum of healthy humans correlating with immune tolerance. Proceedings of the National Academy of Sciences of the USA 106: 2371-2376.

Van Driel, I.R. and Ang, D.K., 2008. Role of regulatory T cells in gastrointestinal inflammatory disease. Journal of Gastroenterology and Hepatology 23: 171-177.

Van Huynegem, K., Loos, M. and Steidler, L., 2009. Immunomodulation by genetically engineered lactic acid bacteria. Frontiers in Bioscience 14: 4825-4835.
Van Nood, E., Vrieze, A., Nieuwdorp, M., Fuentes, S., Zoetendal, E.G., De Vos, W.M., Visser, C.E., Kuijper, E.J., Bartelsman, J.F., Tijssen, J.G., Speelman, P., Dijkgraaf, M.G. and Keller, J.J., 2013. Duodenal infusion of donor feces for recurrent Clostridium difficile. New England Journal of Medicine 368: 407-415.

Verna, E.C. and Lucak, S., 2010. Use of probiotics in gastrointestinal disorders: what to recommend? Therapeutic Advances in Gastroenterology 3: 307-319.

Veshnyakova, A., Piontek, J., Protze, J., Waziri, N., Heise, I. and Krause, G., 2012. Mechanism of Clostridium perfringens enterotoxin interaction with claudin-3/-4 protein suggests structural modifications of the toxin to target specific claudins. Journal of Biological Chemistry 287: 1698-1708.

Videlock, E.J. and Cremonini, F., 2012. Meta-analysis: probiotics in antibiotic-associated diarrhoea. Alimentary Pharmacology and Therapeutics 35: 1355-1369.

Wells, J.M., 2011. Immunomodulatory mechanisms of lactobacilli. Microbial Cell Factories 10 Suppl. 1: S17.

Wolvers, D., Antoine, J.M., Myllyluoma, E., Schrezenmeir, J., Szajewska, H. and Rijkers, G.T., 2010. Guidance for substantiating the evidence for beneficial effects of probiotics: prevention and management of infections by probiotics. Journal of Nutrition 140: 698S-712S. 
